\title{
EDITORIAL
}

\section{Bowel inflammation in cancer patients: the microbiome, antibiotics and interleukin-9}

Microbiome composition can impact disease courses and also immunotherapy outcomes in solid tumours. It is still unclear how the microbiome might impact treatments in oncology, but also how modulation via antibiotics might interfere. Elegant work now identified interleukin-9 and dysbiosis as relevant factors, providing some answers for these questions.

British Journal of Cancer (2020) 123:1469-1470; https://doi.org/10.1038/s41416-020-01030-0

\section{MAIN}

The microbiome has attracted increasing scientific attention in the last 5 years. ${ }^{1-4}$ In light of the better understanding of the composition of what constitutes the microbiome in the gut and in other organs, 5,6 one central question is still out in the open: how much influence the composition of the microbiome exerts on organ function and can we modulate this? There are elegant studies in animal models, indicating, among other things, that there is a direct relationship between the composition of the microbiome in the gut and immunotherapy outcome., $3,7-9$

Looking beyond animal models into the clinical situation, the picture becomes much fuzzier. Do we need to treat patients with antibiotics $^{10-12}$ (or other biome-modulating agents) to induce treatment responses in oncology? Do we need to refrain from giving antibiotics to patients for fear of abrogating anti-tumour responses? Published data show poorer treatment responses in patients with antibiotics, ${ }^{13-15}$ but this is not a surprise for an oncologist: patients who need antibiotic treatment are clearly worse in their overall outlook compared with those who do not need antibiotics. And even one step beyond this: "what constitutes a 'normal' microbiome" ${ }^{16}$ Is there a holy grail of beneficial bugs living in the guts of super-responders? These are questions being investigated currently and we have to wait for more insights before we can move to action in the clinic.

In light of these pressing questions, one aspect now has been addressed in the manuscript from Almeida et al. ${ }^{17}$ This elegant work now brought up interleukin-9 (IL-9) as an induced parameter by specific microbial communities. IL-9 is a well-known immunologically pleiotropic molecule. ${ }^{18,19}$ In inflammatory bowel disease, gut-residing $T$ cells produce high amounts of IL-9. In model systems of colitis, IL-9-producing T cells critically interfered with an intact barrier function of the intestinal epithelium by modulating cellular proliferation and tight junction control. Inhibiting IL-9 ameliorated the inflammation and severity of inflammatory bowel disease. As for cancer diseases, this indicates, in light of the new data from Almeida et al., ${ }^{17}$ that there could be a link to gut inflammation, which enforces anti-tumoural effects through barrier-breaching and bacterial product presence beyond the gut. It is an interesting hypothesis that comes from this: is there a beneficial inflammatory signature that is mediated by IL-9 and resembles a state of colitis? Almeida et al. ${ }^{17}$ found that the host microbiota enhances in vivo T-cell-derived secretion of IL-9, thereby limiting cancer outgrowth (see Fig. 1). So maybe we have to rethink the current clinical concepts for gut inflammation and antibiotic use. We need to understand better inflammatory states

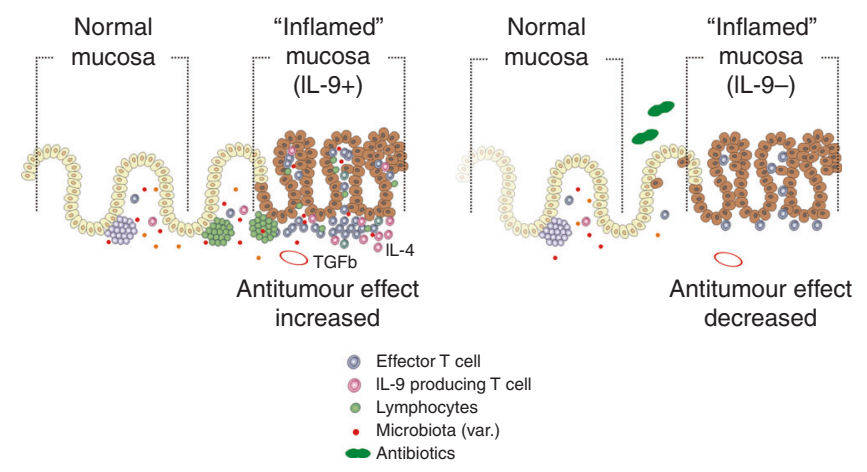

Fig. 1 Differential effects for IL-9 in the mucosa. Schematic summary of the differential effects of microbiome composition (i.e. differing microbial composition and dysbiosis shown on the right panel) on the generation of interleukin-9-producing $\mathrm{T}$ cells.

especially for IL-9 $9^{20}$ and not rush too easily into combating all forms of inflammation. There is more clinical and biological data from translational studies needed to clarify this situation.

\section{ACKNOWLEDGEMENTS}

None.

\section{AUTHOR CONTRIBUTIONS}

N.H. wrote the manuscript and drafted the figure.

\section{ADDITIONAL INFORMATION}

Ethics approval and consent to participate Not applicable.

Data availability Not applicable

Competing interests N.H. is a Subject Editor for the $B J C$.

Funding information No specific funding for this manuscript.

Note This work is published under the standard license to publish agreement. After 12 months the work will become freely available and the license terms will switch to a Creative Commons Attribution 4.0 International (CC BY 4.0). 
Publisher's note Springer Nature remains neutral with regard to jurisdictional claims in published maps and institutional affiliations.

\section{Research Center (DKFZ), Heidelberg, Germany and ${ }^{2} \mathrm{HI}-\mathrm{TRON}$ Helmholtz Institute for Translational Oncology, Mainz, Germany Correspondence: Niels Halama (niels.halama@nct-heidelberg.de)}

\section{REFERENCES}

1. Routy, B., Gopalakrishnan, V., Daillere, R., Zitvogel, L., Wargo, J. A. \& Kroemer, G. The gut microbiota influences anticancer immunosurveillance and general health. Nat. Rev. Clin. Oncol. 15, 382-396 (2018).

2. Gopalakrishnan, V., Spencer, C. N., Nezi, L., Reuben, A., Andrews, M. C., Karpinets, T. V. et al. Gut microbiome modulates response to anti-PD-1 immunotherapy in melanoma patients. Science. 6371, 97-103 (2018).

3. Routy, B., Le Chatelier, E., Derosa, L., Duong, C. P. M., Alou, M. T., Daillere, R. et al. Gut microbiome influences efficacy of PD-1-based immunotherapy against epithelial tumors. Science. 6371, 91-97 (2018).

4. Zitvogel, L., Daillere, R., Roberti, M. P., Routy, B. \& Kroemer, G. Anticancer effects of the microbiome and its products. Nat. Rev. Microbiol. 15, 465-478 (2017).

5. Shui, L., Yang, X., Li, J., Yi, C., Sun, Q. \& Zhu, H. Gut microbiome as a potential factor for modulating resistance to cancer immunotherapy. Front. Immunol. 10, 2989 (2019).

6. Mehta, R. S., Nishihara, R., Cao, Y., Song, M., Mima, K., Qian, Z. R. et al. Association of dietary patterns with risk of colorectal cancer subtypes classified by Fusobacterium nucleatum in tumor tissue. JAMA Oncol. 3, 921-927 (2017).

7. Fares, C. M., Van Allen, E. M., Drake, C. G., Allison, J. P. \& Hu-Lieskovan, S. Mechanisms of resistance to immune checkpoint blockade: why does checkpoint inhibitor immunotherapy not work for all patients? Am. Soc. Clin. Oncol. Educ. Book/ASCO Am. Soc. Clin. Oncol. Meet. 39, 147-164 (2019).
8. Pitt, J. M., Vetizou, M., Waldschmitt, N., Kroemer, G., Chamaillard, M., Boneca, I. G. et al. Fine-tuning cancer immunotherapy: optimizing the gut microbiome. Cancer Res. 76, 4602-4607 (2016).

9. Sivan, A., Corrales, L., Hubert, N., Williams, J. B., Aquino-Michaels, K., Earley, Z. M. et al. Commensal Bifidobacterium promotes antitumor immunity and facilitates anti-PD-L1 efficacy. Science 350, 1084-1089 (2015).

10. Cao, Y., Wu, K., Mehta, R., Drew, D. A., Song, M., Lochhead, P. et al. Long-term use of antibiotics and risk of colorectal adenoma. Gut. 67, 672-678 (2018).

11. Suez, J., Zmora, N., Zilberman-Schapira, G., Mor, U., Dori-Bachash, M., Bashiardes, $S$. et al. Post-antibiotic gut mucosal microbiome reconstitution is impaired by probiotics and improved by autologous FMT. Cell 174, 1406-23.e16 (2018).

12. Gury-BenAri, M., Thaiss, C. A., Serafini, N., Winter, D. R., Giladi, A., Lara-Astiaso, D. et al. The spectrum and regulatory landscape of intestinal innate lymphoid cells are shaped by the microbiome. Cell 166, 1231-46.e13 (2016).

13. Huang, X. Z., Gao, P., Song, Y. X., Xu, Y., Sun, J. X., Chen, X. W. et al. Antibiotic use and the efficacy of immune checkpoint inhibitors in cancer patients: a pooled analysis of 2740 cancer patients. Oncoimmunology 8, e1665973 (2019).

14. Pinato, D. J., Howlett, S., Ottaviani, D., Urus, H., Patel, A., Mineo, T. et al. Association of Prior Antibiotic Treatment With Survival and Response to Immune Checkpoint Inhibitor Therapy in Patients With Cancer. JAMA Oncol. 12, 1774-1778 (2019).

15. Sen, S., Carmagnani Pestana, R., Hess, K., Viola, G. M. \& Subbiah, V. Impact of antibiotic use on survival in patients with advanced cancers treated on immune checkpoint inhibitor phase I clinical trials. Ann. Oncol. 29, 2396-2398 (2018).

16. Elinav, E., Garrett, W. S., Trinchieri, G. \& Wargo, J. The cancer microbiome. Nat. Rev. Cancer 19, 371-376 (2019).

17. Almeida, R. R., Vieira R.d.S., Castoldi, A., Terra, F. F., Melo, A. C. L., Canesso, M. C. C. et al. Host dysbiosis negatively impacts IL-9-producing T-cell differentiation and antitumor immunity. Br. J. Cancer 123, 534-541 (2020).

18. Gerlach, K. \& Weigmann, B. The dichotomous function of interleukin-9 in cancer diseases. J. Mol. Med. 97, 1377-1383 (2019).

19. Matusiewicz, K., Iwanczak, B. \& Matusiewicz, M. Th9 lymphocytes and functions of interleukin 9 with the focus on IBD pathology. Adv. Med. Sci. 63, 278-284 (2018).

20. Purwar, R., Schlapbach, C., Xiao, S., Kang, H. S., Elyaman, W., Jiang, X. et al. Robust tumor immunity to melanoma mediated by interleukin-9-producing T cells. Nat. Med. 18, 1248-1253 (2012). 